\title{
耐离渗压醉母发醭法生产甘油的研究
}

\author{
无锡轻工业学院 无锡酶制剂厂
}

甘油是国防、化工、医药、食品的重要原 料. 随着工业的迅速发展, 甘油的需要量日 趋增加. 在第一次世界大战前, 甘油全部是 从天然油脂㿝化和水解得来. 第一次世界大 战中开始研究并建立了用亚硫酸盐法糖质原 料发醂甘油的工厂. 但因发酵和提炼工艺不 合理, 不经济, 战后都停产了. 从五十年代 后合成甘油工厂才开始陆续建立. 六十年代 前后, 发醭法甘油的研究又开始活跃. 除继 续对亚硫酸盐法进行研究外 ${ }^{11}$, 对具有更多 优点的耐高渗压醉母发酵法研究得更为广 泛. 但据资料记载, 主要还停留在实验室研 究阶段 ${ }^{[2-7]}$. 根据国家需要, 最近二年, 我们 对淀粉质原料耐高渗压醉母发酵法生产甘油 进行较为系统的矿究, 并在无锡酶制剂厂进 行试验生产. 本文简述该研究的概况.

\section{材料和方 法}

一、采样 为了分离耐高渗压醉母, 采 集的样品有蜜饯、甜果、花蜜、蜂蜜、甜汁，常 有糖类物质流经和贮积的土壤和有高浓度排 泄物流经的排水道淤积物等.

二、培养基 除特殊标明外, 实验室所 用培养基均添加含总磷量为 $60-75$ 微克/毫 升的玉米浆和 $0.2 \%(\mathrm{~W} / \mathrm{V})$ 尿素, 初始 $\mathrm{pH}$ 值 3.5一 - 4.0. 酶法葡萄糖含量: 样管培养基为 $40 \%$; 摇瓶培养基为 $25 \%$; 种子培养基为 $10 \%$; 斜面培养基为 $20 \%$, 另加 $2 \%$ 琼脂. 发醉罐发醉培养液为 $20 \%$, 并加人使培养液 含总磷量为 $120-130$ 微克/毫升的玉米浆和 $0.2 \%(\mathrm{~W} / \mathrm{V})$ 尿素, 初始 $\mathrm{pH}$ 值为 4.0.
三、灭菌条件 除固体培养基和种子培 养基用 0.8 公厅/厘米蒸汽灭菌 20 分钟外, 摇瓶培养基只煮沸灭菌, 所用三角瓶先经 $160^{\circ} \mathrm{C}$ 干热灭菌二小时. 发醉罐采用 1 公斤 厘米2 蒸汽实罐灭菌 20 分钟.

四、培养条件 发酵温度 $32-35^{\circ} \mathrm{C}$, 接 种量 $5-10 \%(\mathrm{~V} / \mathrm{V})$, 振荡培养往复次数 140 次/分钟, 振幅 3.5 厘米, 500 裹升三角瓶装 液量为 50 毫升, 开口发醉. 3,000 升发醉罐 摚拌速度 235 转/分钟, 通风量 $1: 0.5-0.8$, 装液量为罐容积 $50-60 \%$ ，也可达 $70 \%$.

五、菌种分离和篎选样管后划线分 离. 菌落挑入斜面培养二天, 接入摇瓶培养 5一6 天. 发醉液离心除去酵母, 纸层析粗测 甘油含量, 择优复篣, 并用变色酸比色法定量 测定发醉液甘油和残糖含量, 直至篮得优良 菌株.

六、分析方法 鉴于开口振荡发醉有较 多水分蒸发, 测定 $\mathrm{pH}$ 值后加水恢复原体积. $\mathrm{pH}$ 值采用上海试剂厂精密试纸测定. 醉母量 的测定是用 3000 转/分钟离心 5 分钟定其醉 母沉淀体积. 糖量测定用蒽酮法 ${ }^{[8]}$. 发醉液 甘油测定用变色酸比色法 ${ }^{[7]}$, 成品测定用比 重法. 总磷用锄蓝比色法 ${ }^{[8]}$. 总氮用凯氏定 氮法 ${ }^{[8]}$. 纸层析溶剂系统为正丁醇: 乙醇 : 水 $=98: 5: 18$.

\section{结果和讨论}

一、菌种筷选 根据耐高渗压醉母生理

本文 1973 年 6 月 12 日收到。 
类型的特点及地区性微生物种类的差异，在 我国南方地区采集各种样品四百余种，分离 初第了二干余株各种耐高渗压醉母, 现摘录 具代表性菌株的特性列于表 1 .

表 1 部分篣得菌株特性

\begin{tabular}{|c|c|c|c|c|c|c|}
\hline \multirow{2}{*}{ 菌 号 } & \multicolumn{3}{|c|}{ 纸层 析 情 况 } & \multirow{2}{*}{$\begin{array}{c}\text { 残糖 } \\
\%\end{array}$} & \multirow{2}{*}{$\begin{array}{c}\text { 多元醇 } \\
\%\end{array}$} & \multirow{2}{*}{$\begin{array}{c}\text { 总糖转 } \\
\text { 华率 } \\
\%\end{array}$} \\
\hline & 甘油 & 阿糖醇 & 赤鯜醇 & & & \\
\hline 2512 & $\mathrm{HH}$ & + & - & 1.6 & 8.6 & 36.0 \\
\hline 2115 & $H$ & - & - & 1.5 & 1.9 & 8.5 \\
\hline 70 & - & H+H & - & 1.3 & 6.5 & 27.0 \\
\hline $61-4$ & $+1+$ & + & - & 2.9 & 9.6 & 40.0 \\
\hline $71-B$ & $H$ & - & - & 2.4 & 5.8 & 25.0 \\
\hline 110 & $H$ & + & + & 3.2 & 8.5 & 33.0 \\
\hline
\end{tabular}

从表 1 可以看到，所篮的耐高渗压䤉母 多数能产生甘油和阿糖醇, 少数只单产阿糖 醇或甘油, 还有少数能产甘油、阿糖醇和赤蘚 糖醇. 根据多次重复试验, 71-B 号单产甘 油, 但得率较低, 发醉条件较难控制. 而从广 东汕头地区采集的蜜饯上分离得到的 61-4 菌株甘油得率高, 阿糖醇极少, 发酵结果稳 定. 故将 61-4 菌株作进一步试验, 并进行了 多次自然选择, 结果获得了目前生产上应用 的较优菌株 61-4-A 8 . 在适当条件下, 其总 綟转化率稳定在 $45 \%$ 以上, 发酵液甘油含量 稳定在 $10-13 \%$.

二、影响发䤃主要因素的摇瓶试验通 过大量试验, 证明在多种因素中, 影响发酵效 果的主要因素是培养基中的总磷量. 从图 1 可以看出, 在摇瓶试验含糖 $25 \%$ 时, 总磷量

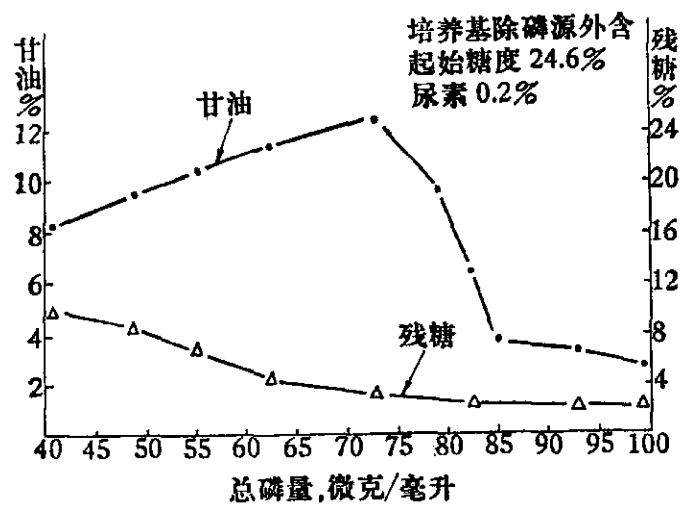

图 1 培养基含的总磷量对发酵的影响
(玉米浆为磷源) 为 $60-75$ 微克/毫升时糖的 转化率最高, 为 $41-48.5 \%$, 以耗糖转化率 计，达到 51-55\%。若总磷量低于最适量, 则残糖增加, 发酵迟缓, 总糖转化率低. 若总 磷量高于最适量, 耗糖加快, 产生酯香味和大 量醅母菌体, 总糖转化率大幅度下降. 与最 适磷量相差越大, 发醉效果就越差. 在以醉 母裔、玉米浆、无机磷为唯一磷源进行发醉试 验时, 表明对酶法盏匋糖液为碳源时, 发醉效 果与磷源无关, 而仅与总磷量有关. 当起始 糖浓度较 $25 \%$ 或高或低时, 最适磷量即随糖 浓度的加大而增高，例如糖浓度为 $16.8 \%$ 时, 最适磷量是 51 微克/裹升, 而糖浓度为 $30.8 \%$ 时, 最适磷量则上升为 78.5 微克/毫 升. 另外, 就是培养液中总氮量有增减时, 对 最适磷量也有一定影响, N/P 一般在 19-25 较合适. 特别要指出的是, 通风效果对最适 磷量有重要影响。例如在发醭生产中, 采用 一般傥拌型密闭发醉罐时, 最适磷量则为 120-130 微克/毫升.

三、三千公升发䤃罐瓜千直接酶法糖液 发䤃试验生产

1. 工艺流程 (见下页)

2. 发酵全过程概况

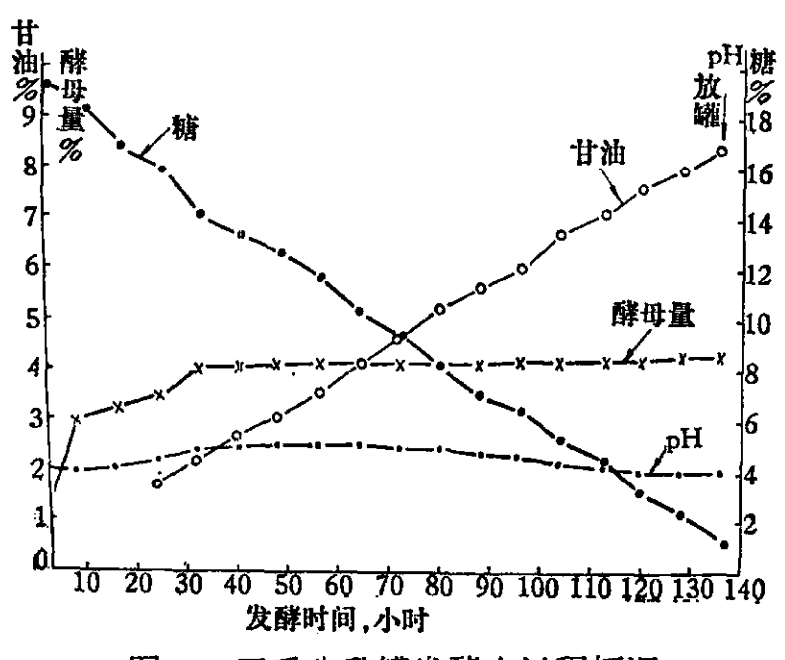

图 2 三千公升罐发醉全过程概况

从图 2 可以观察到: 在整个发䤉过程 中, 发酵液的酵母量前 32 小时是逐渐增加 的. 但当酵母量达到 $4 \%$ 左右, 就基本成为 

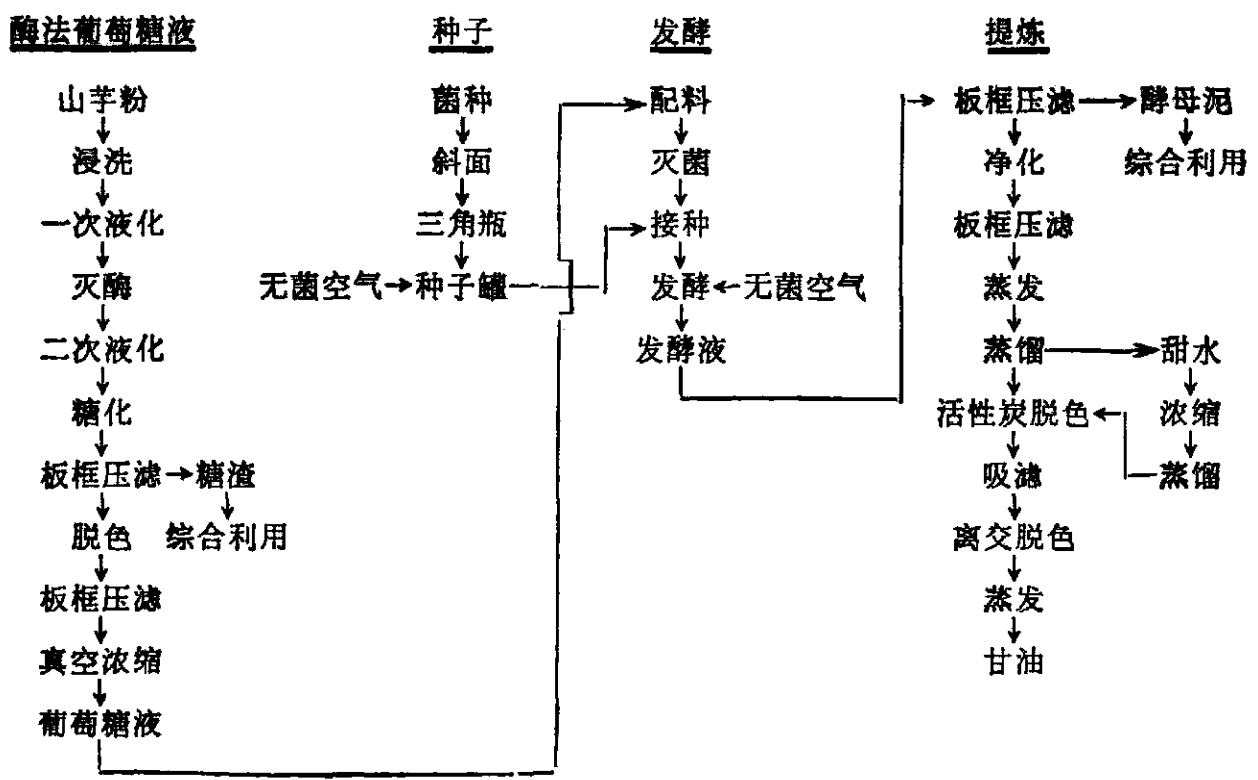

一个动平衡。 $\mathrm{pH}$ 值虽有微小波动, 但全过程 基本在 4-5 之间. 而糖的消耗与甘油的积 累则有一个准量关系。一般是耗 2 度糖, 生 成 1 度甘油，但我们的实验有时超过 Hainy 等提出的发醉甘油最高理论转化率为耗糖的 $50 \%$ 的推论. 当发醉末期残糖量低于 $1 \%$ 时， 这时必须及时放罐,否则有消耗甘油的可能.

在采用典型的通气间歇发酵试验外，我 们还进行了回收酵母作大接种量开口发酵及 用鼓风机代替压缩机通风的试验，也收到了 良好的效果.

\section{3.甘油成品的提炼}

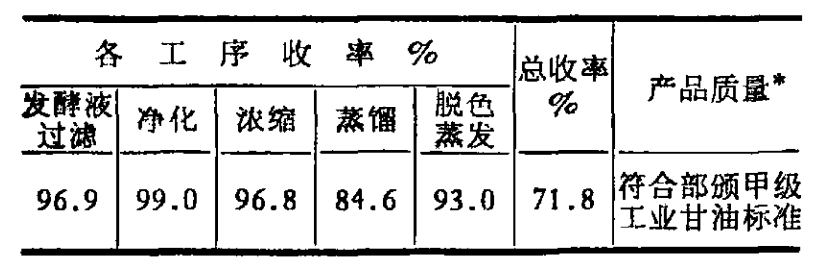

*承苏州肥㿝厂协助化验。

上列数据为四批生产数据的平均值.

由于原料不同，酶制剂中的杂质以及发 酵过程中代谢产物的形成，导致最终发酵液 成分很复杂. 特别当发酵液中残糖量增高, 就会严重影响成品的总收率和质量, 故必须 采取相应的净化程序. 由于蒸馏后甘油有一 定色泽，所以尚需用脱色树脂进行脱色.这些 是与其他甘油生产方法不同的.

结

\section{论}

经过定向选育获得一株经鉴定为 Candida sp. 编号为 61-4-A 8 的产甘油耐高渗压醉 母. 经过三干公升发酵罐多批生产试验，当 山芋粉酶法制糖的得率在 $54 \%$ 以上, 发酵液 原始糖量为 $20 \%$ 左右, 总磷量为 120 -130 微 克/毫升，发酵 5-6 天，甘油含量可稳定在 8.5 克/100 毫升, 总糖转化率平均达到 $41 \%$, 提炼总收率平均为 $72.2 \%$ ，每吨甘油耗瓜干 6 吨左右，质量符合甲级工业甘油标准．鉴 于发酵操作简单,不易染菌,设备要求不高等 特点,发酵和提炼均较稳定. 这条工艺路线是 可行的. 若生产规模适当扩大，进一步选育 菌种,改进工艺,注意菌体综合利用，则在经 济效果上可以与其他甘油生产方法相比.

\section{参文嗝}

[ 1] Hairis, J. E. \& Hajny, G. J., 1960 J. Biochem. and Microbiol. Technol. Eng., 12, 9-24.

[2]大西博, 1962 日本特许公报, 昭 37-12450.

[3] 大西博, 1962 日本特许公报,昭 37-3545.

[4]大西博, 1964 日本特许公报, 昭 39-27497.

[5] Button, D. K., Garver, J. C. \& Hajny, G. J., 1966 J. Appl. Microbiol., 14, 292-294.

[6] 张树政、杨廉婉、王惠逢, 1962 微生物学报, 8, 369376.

[7] Marguerite Lambert \& Neish, A. C., 1950 Can. J. Res., 28, 83-89.

[8] 张宽厚, 1962 细菌生理学,人民卫生出版社. 